\title{
A novel approach to polymer dissolution - modular CPS
}

\author{
Jamiel Muhor BASF Australia Ltd, Australia \\ Lewis Utting Utting Associates Pty Ltd, Australia \\ Ronald Michalczyk BASF Corporation, USA \\ Mark A. Marcus ProProcess, South Africa \\ Tanya Marcus ProProcess, South Africa
}

\begin{abstract}
Thickening of tailings material produced in the mining, chemical, water supply and sanitation industries started in 1905 in conventional thickeners that were used well into the 1960s. The development of water soluble polymer flocculants in mineral processing is necessary to make thickening, clarification and tailings treatment processes effective. BASF has a range of polymers that are used for these processes in a variety of industries.
\end{abstract}

Ever increasing tonnages of low grade ore or the treatment of more challenging substrates have highlighted limitations in the conventional systems used for hydration and dissolution of polymers that make them ready for use. When these systems are pushed to nameplate capacity, field observations indicate that plant availability can be impacted with symptoms such as foaming, powder blockages and gelatinous masses limiting any improvements.

Where significant process streams require treatment with a polymer, arguably the most economical product form is a powder, which is then pneumatically transferred into a storage silo. Hydration and dissolution of the polymer before use is typically conducted in batch process where separate powder storage, hydration tank and ageing tanks are used. These conventional systems, although scalable to an extent, have limitations and require large footprints, services and civils to allow the polymer to be effective.

For example, typical systems of this design type are used where polymer dissolution rates or equipment duty required is $<500 \mathrm{~kg} / \mathrm{hr}$. These systems are typically made to order with lead times on detailed design, engineering and fabrication of up to six months. Limitations on hydration systems have been largely factored around powder handling, initial wetting out of the polymer while ensuring its integrity and maintaining the performance of the polymer.

A novel approach was taken to designing a modular, continuous polymer system capable of producing 1600 $\mathrm{kg} / \mathrm{hr}$ of dry polymer into concentrated solution with minimal civil requirements that was delivered within 6 8 months and has now been operating in a hostile environment for over two years. This paper focuses on design considerations for a Modular Continuous Polymer System (CPS).

\section{Introduction}

Thickening of tailings material produced in the mining, chemical, water supply and sanitation industries started when John Dorr invented the Dorr Thickener in 1905 (Mining Foundation of the Southwest, 1997). These conventional thickeners were used well into the 1960s until the development of polymer flocculants 
allowed for a denser thickener underflow and lead to the development of high rate thickeners in the 1970s. This was followed by the invention of high density and deep cone paste thickeners a decade later (Patterson and Cooke, 2014). The underflow and paste quality produced in these thickeners and the resultant tailings dam is strongly influenced by the selection of polymer.

In addition to selecting the correct polymer for optimum thickening and tailings deposition the preparation, transfer and injection of the polymer is of utmost importance to maximize the efficiency of the resultant polymer solution. BASF in conjunction with preprocess have supplied one of the largest continuous polymer plants in the world, as well as one of the world's largest batch polymer plants for a mining application. This paper focuses on design considerations for a modular continuous polymer make-up system.

Modular plants are ideal for use in remote locations. The off-site assembly greatly reduces construction costs on site. Making use of containerized plants further optimizes the structural steel requirements of the plant and aids in the transportation of the modules to site. Additionally, the plant can be trial assembled and tested prior to shipping reducing the risk of site modifications. The individual modules can be designed such that they stack on top of each other, thus reducing the plant footprint. This can aid in the reduction of civil costs in locations where unsuitable soil conditions (clay soil environment) prevail and supporting soil needs to be imported. Steel raft foundations have been developed that can be manufactured locally or transported to site negating the requirement for civil works.

\section{Main system components}

The continuous polymer make-up system comprises of five unit operations:

- Polymer off-loading.

- Polymer dry transfer.

- Polymer hydration.

- Polymer dissolution.

- Polymer solution dosing.

Each of the components is detailed in the following sections.

\section{$3 \quad$ Batch hydration versus continuous hydration}

Conventional polymer hydration has usually taken place in a batch type process whereby the hydration tank is separate from the polymer ageing and storage tanks. Where large volumes of polymers are required, tank sizing with adequate redundancy with duty standby arrangement presents challenges with regards to overall footprint, fabrication, shipping and overall costs.

Utilizing a modular continuous hydration concept where majority of components would fit inside the typical transportation window allowed for complete fabrication of items off-site.

The following table below shows a direct comparison of the capital requirements for a typical batch versus continuous hydration and dissolution system when the dry polymer design demand is $1600 \mathrm{~kg} / \mathrm{hr}$ at a design concentration of $0.65 \% \mathrm{w} / \mathrm{v}$ with active dissolution time of 40 minutes.

The main benefit in operating a batch system is the ability to design in high level of contingency through having a stand along storage system. However, there also many ancillary components that are not considered below which contribute to challenges when economically designing a batching system at this capacity including: structural steel supports, access stairways and landings, civil works, agitator size, transfer pump housing etc. 
Table 1 Polymer preparation plant comparison for $1,500 \mathrm{~kg} / \mathrm{hr}$ system

\begin{tabular}{ccccc}
\hline Type of polymer preparation system & Mixing tanks & Transfer pumps & Storage tanks & Dosing pumps \\
\hline Conventional batch system & $3 \times 60 \mathrm{~m}^{3}$ & $3 \times 180 \mathrm{~m}^{3}$ & $3 \times 90 \mathrm{~m}^{3}$ & $2 \times 128 \mathrm{~m}^{3} / \mathrm{hr}$ \\
New continuous system & $4 \times 42 \mathrm{~m}^{3}$ & 0 & 0 & $1 \times 128 \mathrm{~m}^{3} / \mathrm{hr}$ \\
\hline
\end{tabular}

\section{$4 \quad$ Polymer off-loading}

For operations that use large quantities of polymer, the preference is for the polymer powder to be transported to site in specially designed inter-modal containers (POD) to avoid the handling of bulk bags and improving the EHS conditions for the customer. Intermodal containers are able reduce the transport footprint yielding freight savings per container as outlined in the below table.

Table 2 Polymer supply options

\begin{tabular}{cccc}
\hline Bag mass (kg) & Number of bags & Total mass (kg) & Improvement with intermodal \\
\hline 800 & 20 & 16,000 & $25 \%$ \\
20,000 & 1 & 20,000 & \\
\hline
\end{tabular}

Once on site, the pod is loaded on to a tilt truck and is connected via a 10-inch hose to a rotary feeder allowing the polymer to be gravity fed and transferred into the polymer storage system (PSS) using a pneumatic transfer system specially designed for the task, which ensures that the temperature is optimal for transfer. The silo headspace is humidity controlled to prevent clumping of the polymer within the silo. Similarly, moisture build up in the transfer lines that could form blockages is negated by blowing through dry air. The lines are blown clean prior to and post the transfer process. A typical transfer of $20,000 \mathrm{~kg}$ of powder polymer can take around 60 minutes to complete.

A major advantage of the system is that it is self-contained. Site assembly is minimised once the POD is positioned, piped up and ready for operation. The off-loading system is fully automated and controlled using a specific start-up and shut down procedure and has been designed to utilise conventional transfer equipment from established and well known pneumatic transfer brands to minimise risk, ensure a trouble free start up and continued parts support.

The PSS is equipped with a dust extraction system fitted with anti-static filter bags that is used to mitigate the polymer content of the exiting conveying air. Reverse jet filters are preferred for cleaning the filter bags and these systems can be modified to suit any climate conditions. Inspection hatches located at the top of the PSS are accessed via non-slip flooring. The PSS is also fitted with large manholes on the shell to enable cleaning and access and inside of the PSS an epoxy coating is applied to prevent static build up.
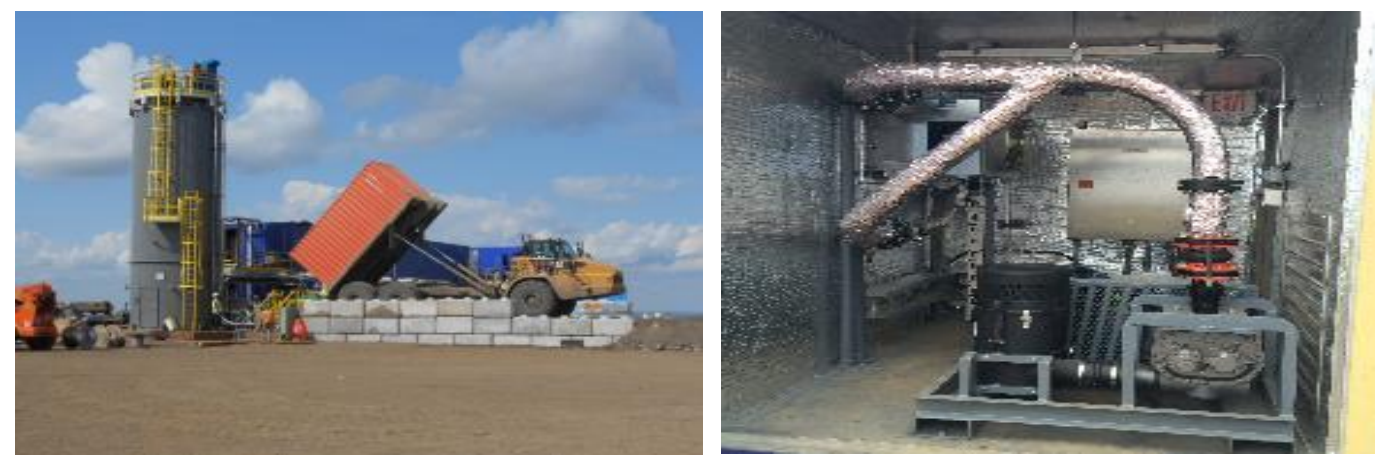

Figure 1 Polymer off-loading facility and equipment 


\section{Dry polymer transfer}

The PSS skirt is used to house the polymer dosing equipment and other ancillary equipment. The PSS is equipped with vibration pads to ensure no bridging of the dry polymer during use with the activation of the vibration pads integrated into the control sequence, which also ensures that the vibration pads are not activated too often, potentially resulting in polymer compaction and silo inoperability. Dehumidifier units are employed to maintain a low moisture content of the air in the PSS skirt.

Polymer is gravity fed from the PSS into intermediate storage silos which are equipped with BASF's proprietary dry polymer dosing systems called the Alcotech Aerowet ${ }^{\mathrm{TM}}$. Each Aerowet is used for dilute phase transport of the dry polymer to the wetting apparatus at the controlled dose rates to meet the requested polymer concentrations. The units consist of a screw feeder with variable frequency drive (VFD) motors feeding a transfer line connected to a side-channel blower enabling pneumatic transfer of the polymer. During commissioning the VFD is calibrated to ratio the amount of powder dosed resulting in a straight-line correlation.

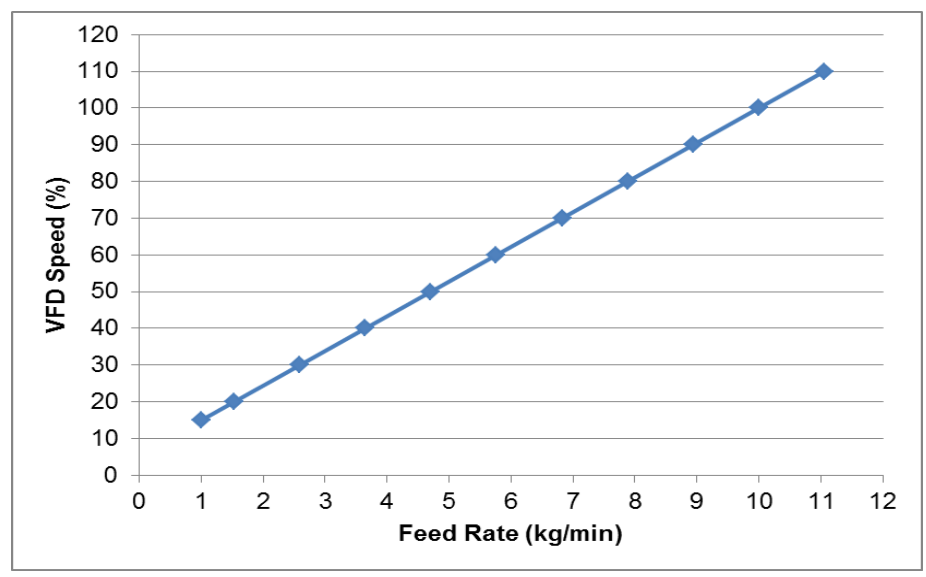

Figure 2 Typical screw feeder calibration graph

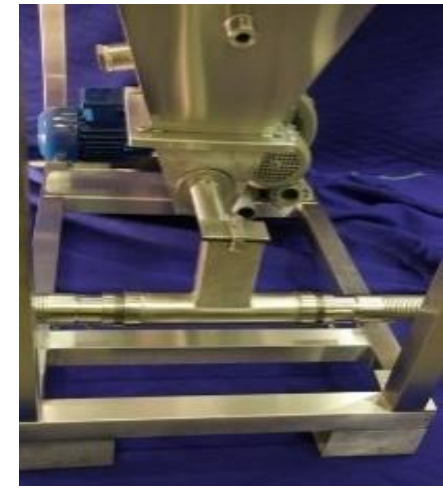

Figure 3 Typical AerowetTM unit

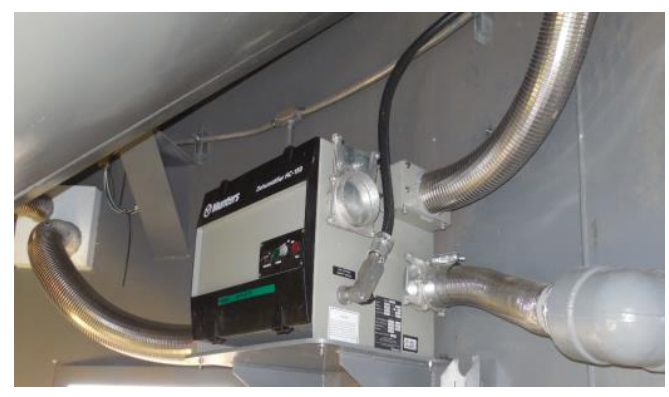

Figure 4 Mounted dehumidifier 


\section{Polymer hydration}

The pneumatically conveyed polymer is contacted with water in the Jet Wet Head ${ }^{\circledR}$ (JWH), BASFs propriety wetting apparatus which initiates the hydration and dissolution process of the polymer.

The JWH is located in the initial compartments of the dissolution trains. The correct operation of the wetting apparatus is key to the operation of the plant and can only be achieved with tight control of the flowrate and pressure of water feeding the unit. The water to powder dosing ratio is under strict process control to optimally run the plant, with the metered water flow directing the screw feeder rate to meet the polymer concentration set point.

The JWH units ensure that polymer powder is properly hydrated and avoids the formation of un-wetted polymer and in turn presence of fisheyes in solution. The JWH consists of an arrangement of specially designed nozzles to provide an effective spray and that can handle process or contaminated water containing particulate matter of up to $5 \mathrm{~mm}$. The unit is of static operation and therefore low maintenance and is fitted with a Perspex cylinder directing the hydrated polymer into the first dissolution tank of the polymer train.

In regions where water sources contain high fractions of colloids or solvents an additional spray bar is installed to in the first two chambers of the dissolution tank to suppress any foaming, which could potentially lead to spillages and polymer wastage.

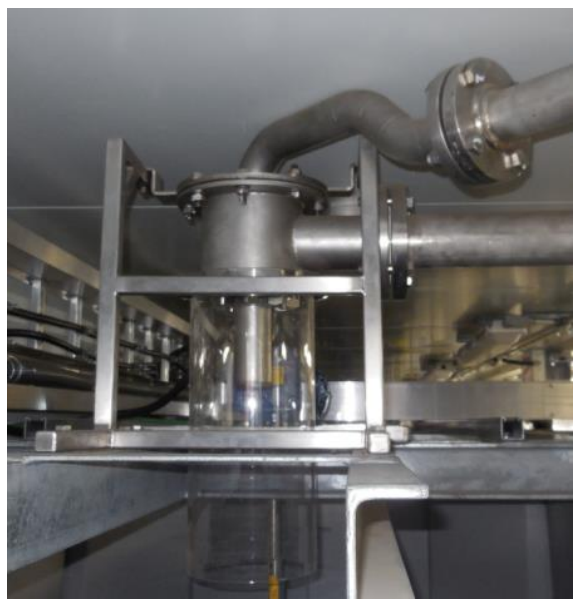

Figure 5 Polymer wetting system

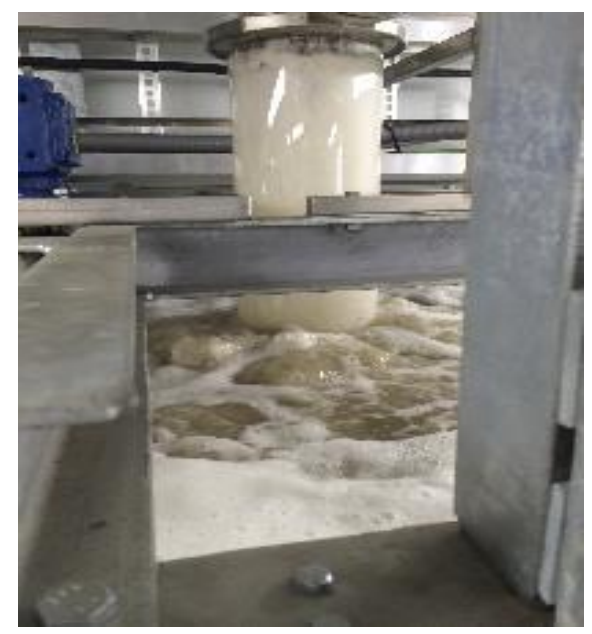

Figure 6 Foam formation due to process water quality 


\section{$7 \quad$ Polymer dissolution}

Each compartment in the dissolution tank is equipped with a low shear agitator specifically designed to effective mix the concentrated polymer avoiding shearing of the polymer chains. The agitators in the first two compartments are designed to not only accelerate the dissolution of the polymer in solution but also to mitigate any foam formation produced during the hydration stage in the JWH. Furthermore, the agitators are designed in such a manner as to degas the solution. Gas pockets in long transfer lines need to be avoided as they can upset the dosing control and application of the polymer into the slurry to be treated.

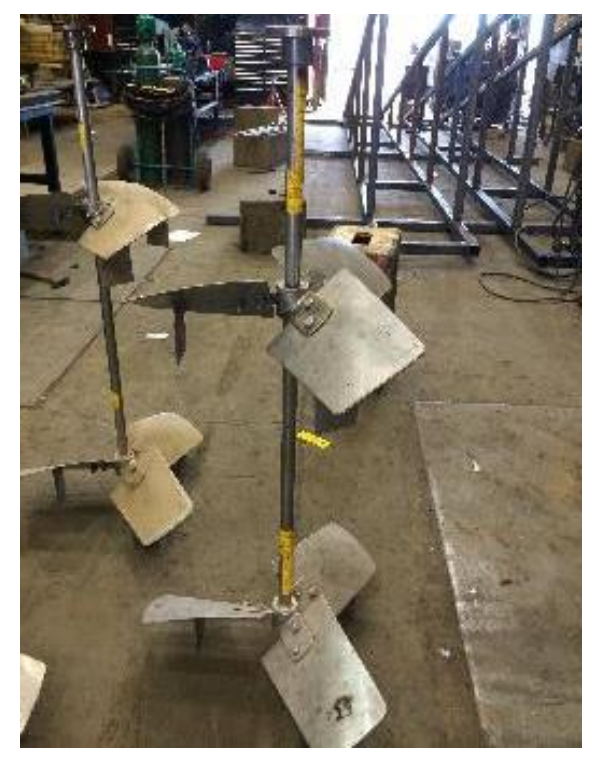

Figure 7 Double blade agitator

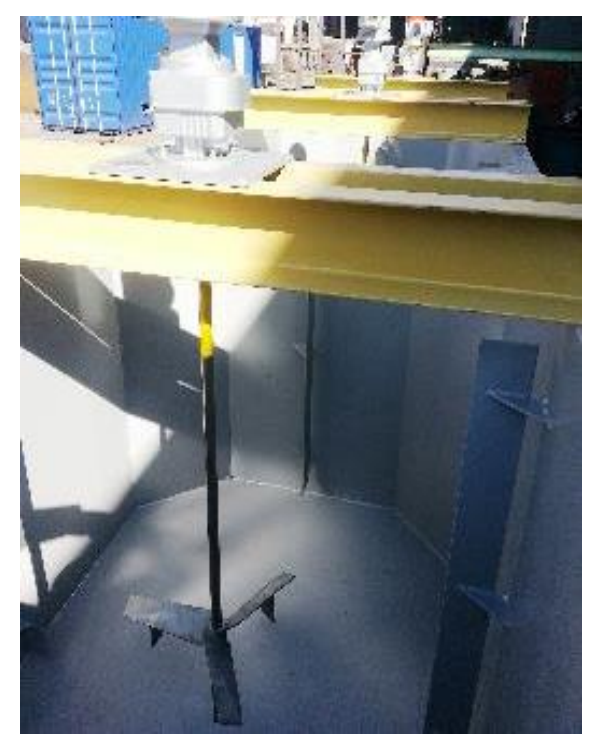

Figure 8 Single blade agitator

The tank compartments are all arranged in a horizontal under/over flow arrangement, ensuring that the most aged dissolved polymer is first removed from the tank. Furthermore, this type of flow arrangement ensures that the hydrated polymer powder is drawn into solution, without by-passing further downstream. Square tanks were chosen mainly for their modularisation ability with the tanks having the capability to be fully drained for winterisation purposes, if required. 


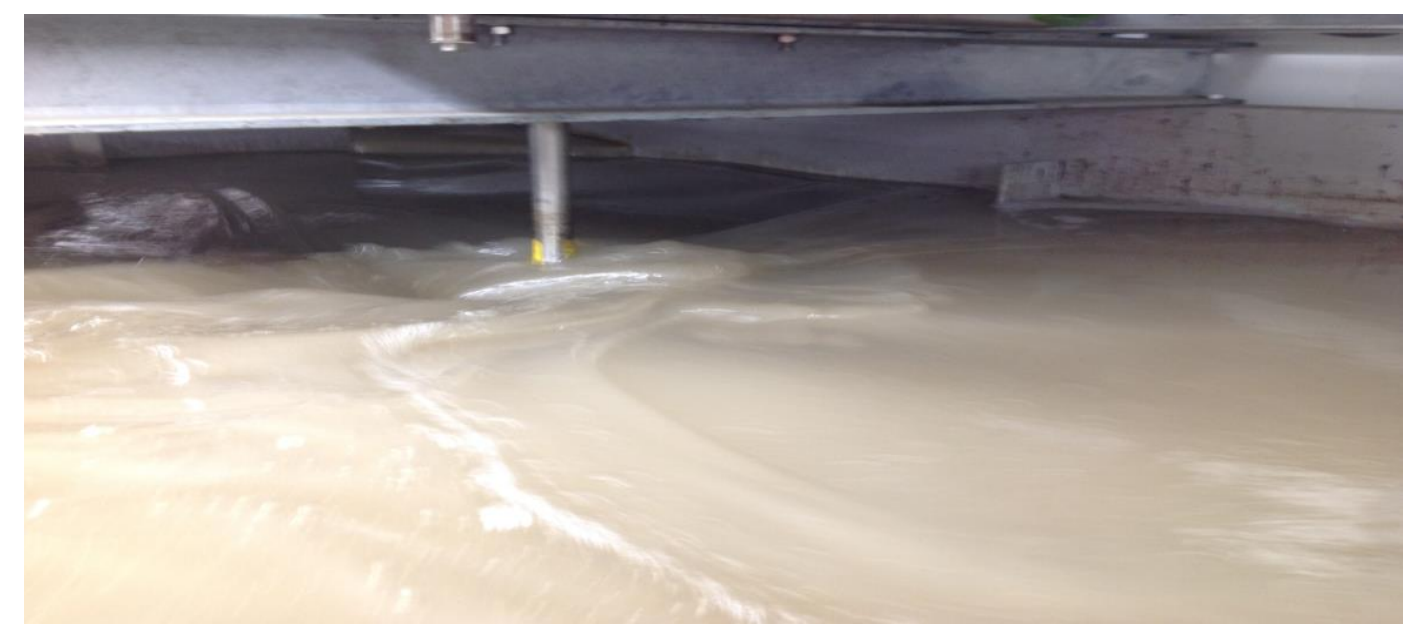

Figure 9 Polymer solution mining in tank

\section{Polymer viscosity}

Another important component of the process is knowing the polymer design viscosity which impacts the hydraulic profile in the dissolution tank. This needs to be considered for plant control purposes as significant time delays can be experienced from when a change is initiated to when the change is realized.

There are several factors that influence the viscosity of a polymer solution including molecular weight, concentration, temperature, and the nature of the process water. For this reason, as part of the design process for the polymer plant it is important to run a series of laboratory tests on selected polymer samples exposed to differing conditions allowing a viscosity profile to be prepared.

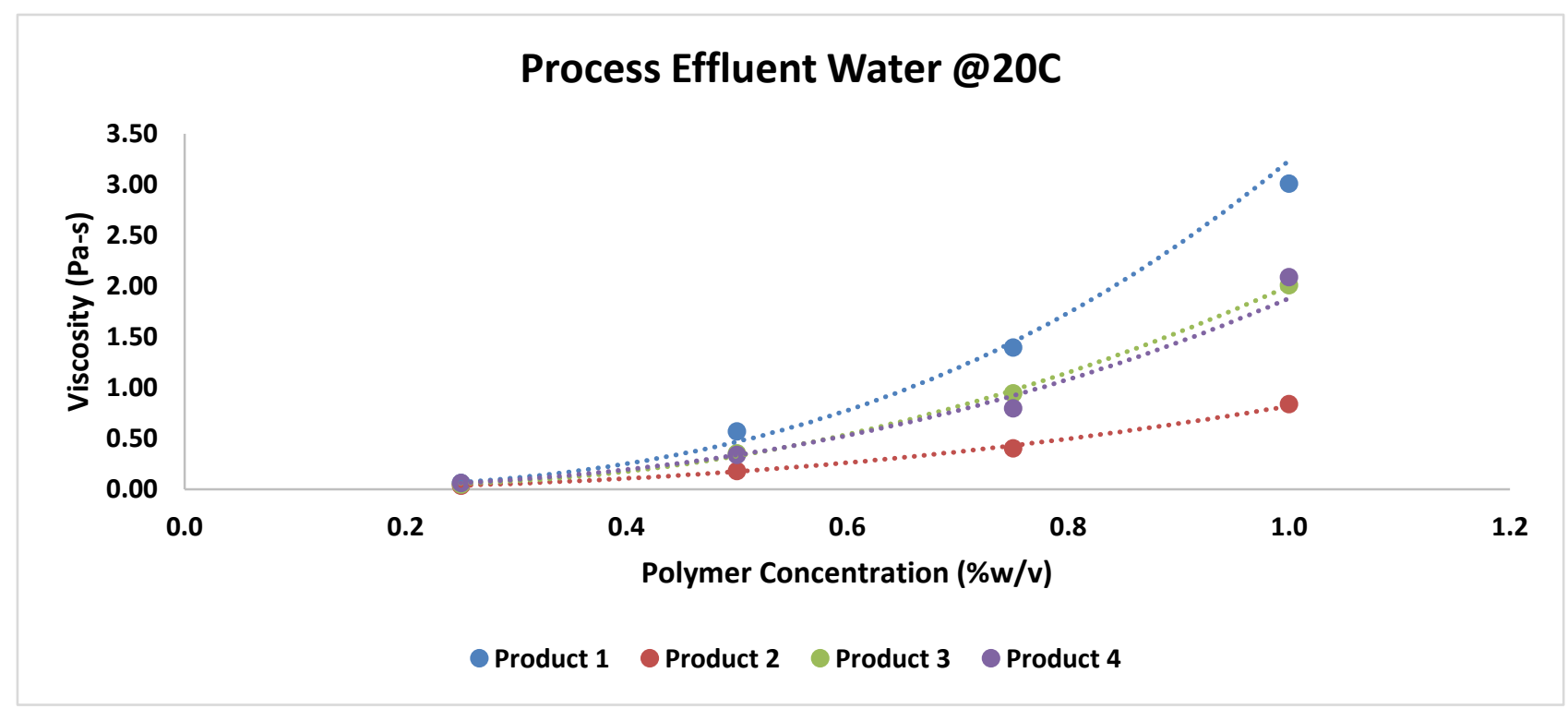

\section{Figure 10 Typical viscosity profile of various polymer solutions}

Using such information, we can define an optimal operating range for viscosity, however with the variable day to day conditions experienced in plant processes, it is always a requirement to build in a good safety factor, and therefore in this case with the plant having multiple agitators across the chambers, these can be turned on and off as required.

Based on a standard design of $2.0 \mathrm{~Pa}^{-5}$, polymer concentrations can be increased to meet the viscosity target, ultimately reducing the hydration water requirement and flow requirement when compared with lower polymer concentrations. Where batch units are considered, polymer viscosity can also hamper transfer times 
from hydration tank to storage tank, adding an additional 10 15 mins onto cycle times while relying on a single critical component i.e. transfer pump.

\section{$9 \quad$ Polymer solution dosing}

Progressive cavity dosing pumps fitted with pressure relief valves and accurate flow measurement are the preferred and selected method to dose the polymer solution to the field. When designing for the selected pump, the operator will provide the appropriate data and information allowing for the pump calculations to be completed in-house and then reviewed and confirmed by the pump manufacturer.

The pump skids are designed as a duty/stand-by system that are easy to change over and strip out for repair or replacement. The selected pumps are low shear to avoid polymer chain breakage and can be available to meet high flow rates $\left(<150 \mathrm{~m}^{3} / \mathrm{hr}\right)$ and high discharge pressure $(<3000 \mathrm{kPa})$.

For applications where low environmental temperatures prevail all pipes can be fully drained for winterisation and an allowance can be made for a system to displace the polymer solution in the pumps with a low freezing point fluid.

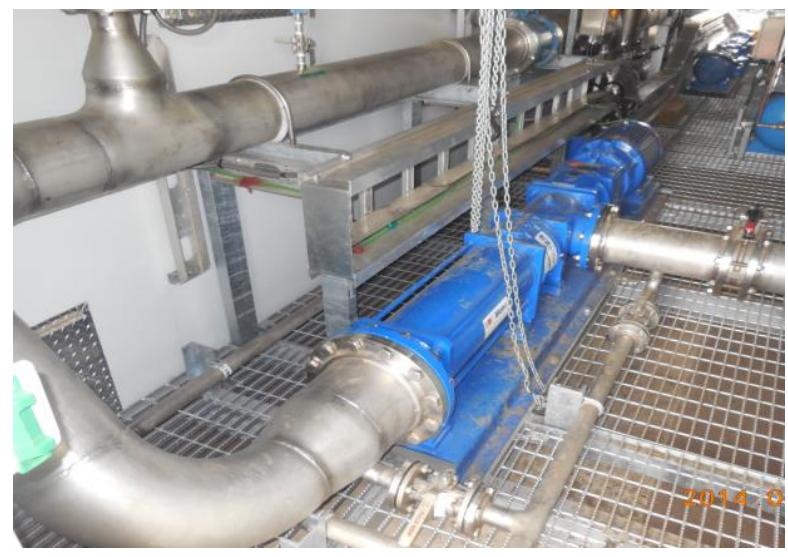

Figure 11 Typical modular plant polymer dosing pump system

\section{Ancillary system components}

The modular polymer plant has many other components, which complete the design and processing system. The following components compliment the system to deliver the final package.

\section{Utility}

Instrument air is required on the plant for control purposes. Further equipment requiring air are the silo filters and silo vibrators (although these can also be electrically actuated). Two screw compressors are employed for this purpose with a duty/stand-by configuration. Screw compressors are chosen for this application due to their small footprint. The compressors are fitted with integral desiccant dryers that are designed to ensure that the dew point is such that moisture do es not form in the equipment. A specially designed header pipe can be used for air storage instead of a purpose-built pressure vessel in order to optimise plant footprint. 


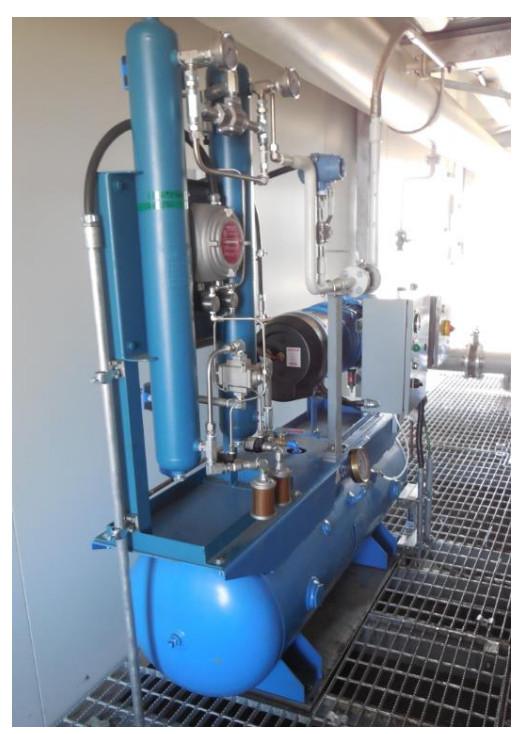

\section{Figure 12 Plant screw compressor}

The plant is delivered together with an electrical container which is insulated and split into three compartments. The first compartment houses the HVAC equipment, the second the MCC, and the final compartment is used as either a marshalling room or for the PLC/DCS. Air conditioners are also installed in the container prior shipment; thus, minimal work is required on site. The MCC is contains a UPS, low voltage lighting circuit and the variable frequency drives.

\section{Container considerations}

The intermodal containers can be insulated for harsh environmental conditions and the geometry of the containers lends itself well to this. The containers are fitted with ventilation systems to ensure sufficient air changes take place to provide a safe working environment for personnel.

As the containers are modified and fitted out at the preferred point of manufacture, to enable protection for shipment false walls are fitted which can be easily removed prior to installation. Once on site the panels are removed and the individual containers are coupled up and weatherproofed. Additionally, to minimise site labor during installation, selected electrical cables are preinstalled, rolled back prior to transport and are easily reconnected on site.

All container external structures are designed to be simple bolt on, with the weight of the container being used to fix structures in place.

\section{Control}

The control hierarchy is critical for correct polymer dosing. The polymer demand by the downstream operation is linked to the polymer make-up and dosing facility. The water to powder ratio is critical for the polymer usage at the end user, this is achieved by measuring the make-up water demand and adding the correct amount of polymer powder via the VFD controlled Aerowet ${ }^{\mathrm{TM}}$ units. Interlinking of two or more hydration units requires steady control. A 65\% turn down capacity is achievable for this system.

\section{Fabrication and site build period}

Standard processing equipment and units are employed, thus negating the use of specially designed equipment which leads to a reduced fabrication period. The site assembly and commissioning time is short 
as all equipment has been assembled and pretested in the construction yard. This minimised the construction and commissioning crews that are required on site. Typically, when construction occurs on site the civil foundations need to be laid before other construction activities can commence. Using modularised systems allows for the plant to be fabricated at the same time as civil foundations are being poured and thus reduces this delay.

The use of sealed containers to transport the plant to site reduces the amount of losses that are experienced during transportation. All equipment meets normal transportation envelopes with only the silos being break bulk.

Off-site fabrication improves site safety. It also reduces the number of specialised artisans required on site as these services can be completed in the fabrication yard. The plant quality is also improved. Overhead costs (crane hire, construction management, and etcetera) is vastly reduced as containerised plants are quick to install.

\section{Conclusions}

Continuous, modular polymer hydration systems can be designed to remove the complexity normally associated with large batch polymer equipment:

- Shipping times can be greatly reduced with equipment remaining within shipping scales.

- Footprint and civil requirements are generally lower when compared with a batch hydration system.

- Site build period can be greatly reduced due to offsite testing and no civil foundations required.

- Typical cost savings on fabrication materials alone can be $>20 \%$ when compared with conventional batch polymer equipment.

\section{Bibliography}

BASF Customer Engineering Solutions

http://www.miningfoundationsw.org/John_Dorr

Patterson and Cooke, 'Thickener Course Notes', pp. 13 